\title{
ADEQUACY OF THE CURRENT RECOMMENDED DOSAGE OF CIPROFLOXACIN IN PRETERM AND TERM NEONATES WITH SEPSIS
}

\author{
S. Manvizhi ${ }^{1,2}$, B.S. Mathew ${ }^{3}$, Anil K. Kuruvilla ${ }^{4}$, Kalpana Margaret Ernest ${ }^{5}$, Saravana \\ Kumar $^{6}$, V Balaji ${ }^{7}$, Vigil James ${ }^{8}$, Denise Fleming ${ }^{9}$ \\ ${ }^{1}$ P.G. Demonstrator, Department of Pharmacology, Christian Medical College Hospital, Vellore, Tamil Nadu, India \\ ${ }^{2}$ Assistant Professor, Department of Pharmacology, Government Vellore Medical College Hospital, Adukkamparai, Tamil Nadu, India \\ ${ }^{3}$ Professor, Department of Pharmacology and Clinical Pharmacology Unit, Christian Medical College Hospital, Vellore, Tamil Nadu, India \\ ${ }^{4}$ Professor, Department of Neonatology, Christian Medical College, Vellore, Tamil Nadu-4, India \\ ${ }^{5}$ Professor, Department of Pharmacology and Clinical Pharmacology Unit, Christian Medical College Hospital, Vellore, Tamil Nadu, India \\ ${ }^{6}$ Associate Research Officer, Clinical Pharmacology Unit, Christian Medical College, Vellore, Tamil Nadu, India -04 \\ ${ }^{7}$ Professor, Department of Microbiology, Christian Medical College, Vellore, Tamil Nadu, India - 04 \\ ${ }^{8}$ Department of Neonatology, Christian Medical College, Vellore, Tamil Nadu, India - 04 \\ ${ }^{9}$ Honorary Processor, Department of Pharmacology and Clinical Pharmacology Unit, Christian Medical College Hospital, Vellore, Tamil \\ Nadu, India
}

\section{ABSTRACT}

Objectives: To determine the percentage of neonates with sepsis, on treatment with standard recommended dose of intravenous ciprofloxacin, who had the serum ciprofloxacin Peak concentration: Minimum inhibitory concentration (Cmax:MIC), within the acceptable range.

Design: Observational study design

Intervention: In the Neonatology ICU, ciprofloxacin was initiated at a dose of $10 \mathrm{mg} / \mathrm{kg}$, twice daily in 95 neonates diagnosed with sepsis. On day 3 of ciprofloxacin, blood specimens were collected to measure the trough and peak concentrations of ciprofloxacin and were measured by high performance liquid chromatography. The MIC was measured if the blood culture was positive. When the blood culture was negative, the reference values for the MIC from 'The Clinical and Laboratory Standard Institute Guidelines' were adopted.

Main outcomes: Minimum inhibitory concentration and serum concentrations of ciprofloxacin

Results: Blood culture was positive in 14 babies. The mean $( \pm$ SD) trough concentrations of ciprofloxacin in term, preterm and very preterm neonates was $3.21( \pm 1.99), 2.54( \pm 1.26)$ and $4.01( \pm 1.80) \mu \mathrm{g} / \mathrm{mL}$ respectively. The mean $( \pm \mathrm{SD})$ peak concentration of serum ciprofloxacin in term, preterm and very preterm neonates was, $12.55( \pm 4.945) 8.68( \pm 3.61)$ and $12.07( \pm 3.63) \mu \mathrm{g} / \mathrm{mL}$, respectively. The percentage of neonates who achieved the acceptable Cmax /MIC ratio was predicted to be $74.07 \%$ if the strain was sensitive, $7.41 \%$ if intermediate and zero for resistant strains.

Conclusion: The current recommended dose of intravenous ciprofloxacin in neonates in India may be adequate for treating sepsis due to susceptible organisms. For the treatment of sepsis caused by organisms with intermediate susceptibility, higher dosing regimens may be needed.

Keywords: Cmax, MIC, Neonates, sepsis

Article Info: Received 11 April, 2017; Review Completed 11 May, 2017; Accepted 11 May, 2017; Available online May 15, 2017

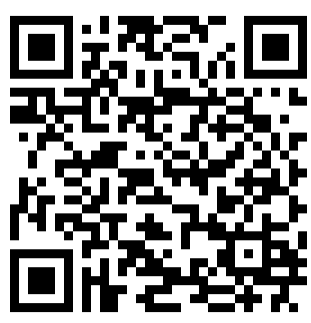
Cite this article as:

Manvizhi S, Mathew BS, Kuruvilla AK, Ernest KM Kumar S, Balaji V, James V, Fleming D, Adequacy of the current recommended dosage of ciprofloxacin in preterm and term neonates with sepsis, Journal of Drug Delivery and Therapeutics. 2017; 7(3):102-105

DOI: http://dx.doi.org/10.22270/jddt.v7i3.1446

*Address for Correspondence

B.S. Mathew, Professor, Department of Pharmacology and Clinical Pharmacology Unit, Christian Medical College Hospital, Vellore, Tamil Nadu, India.

E-mail: clinpharm@cmcvellore.ac.in 


\section{INTRODUCTION}

Neonatal sepsis which refers to a group of physical and laboratory findings in response to invasive infection within the first thirty days of life, ${ }^{1}$ is ranked high among the common causes of death in neonates. The incidence of neonatal sepsis in India is 30 per 1000 live-births. ${ }^{2}$ According to the 2010 WHO statistics, neonatal sepsis accounts for $6 \%$ and $7 \%$ mortality among children less than five years of age, worldwide and in India respectively. ${ }^{3}$

According to National Neonatal Perinatal Database (2002-03), the most common cause of sepsis is Klebsiella pneumoniae, followed by Staphylococcus aureus and Escherchia coli in babies born both within and outside the hospital. Majority of Klebsiella pneumoniae isolates are sensitive to amikacin $(114 / 365$, $31.23 \%$ ), followed by ciprofloxacin (102/381, 26.8\%) among inborn babies. Most of the Staphylococcus aureus isolates, were sensitive to vancomycin $(11 / 28$, $32.3 \%)$ and ciprofloxacin $(27 / 85,31.8 \%)$ in the babies born outside. Most of the E.coli isolates were sensitive to Amikacin, followed by ciprofloxacin. ${ }^{2}$

Ciprofloxacin, with concentration dependent killing, is safe $^{4,5}$ and efficacious in sepsis produced by multiresistant organisms. ${ }^{6-8}$ Zelenitsky et al and Kashuba et al have reported a $\mathrm{C}_{\max } / \mathrm{MIC}$ ratio of $>10$ to be adequate to prevent resistance to this drug. ${ }^{9-11}$ With a lower Cmax in children compared to adults, it was suggested that ciprofloxacin needs to be administered at a dose of 10 $\mathrm{mg} / \mathrm{kg}$, eight hourly for resistant organisms. 12 Ciprofloxacin was eliminated slower in neonates (t1/2 $2.73 \mathrm{~h}$ ) compared to the $1 \pm 5$ year age group (t1/2 1.28 h) 13 . Differences in body weight, hepatic and renal function between preterm and term babies, suggested the need for different dosing regimens for antibiotics like gentamicin. ${ }^{14}$

The goal of this study was to determine the incidence of preterm and term neonates who attained therapeutically acceptable Cmax/MIC ratio, at the current recommended dose of $10 \mathrm{mg} / \mathrm{kg}$, twice daily, when treated for sepsis.

\section{MATERIALS AND METHODS}

The study was approved by the Institutional Review Board of our hospital. Babies admitted to the Neonatology intensive care unit and who required IV ciprofloxacin were recruited into the study, after obtaining written informed consent from the parent. Only babies above 28 weeks of gestational age and treated with IV ciprofloxacin for minimum of three days were included. And babies who were, critically ill, or in shock were excluded. Baseline details such as age, sex, birth weight, measured biochemical parameters and concurrent medications were recorded.

After specimen was collected for blood culture, ciprofloxacin was initiated in babies having suspected bacterial sepsis. The dose of ciprofloxacin was $10 \mathrm{mg}$ $/ \mathrm{kg} /$ dose, administered as a 30 minute IV infusion. Sample collection for ciprofloxacin assay was done on Day 3 (dose 5 or dose 6). Both specimens for measuring trough and peak ciprofloxacin concentration were collected into polypropylene eppendorfs. Peak specimens were collected within 10 minutes after discontinuing ciprofloxacin infusion. It was ensured that specimens were not collected from the same limb that ciprofloxacin was administered. Specimens were centrifuged, serum separated and stored at $-70^{\circ} \mathrm{C}$ till analysis.

The blood culture and sensitivity report was followed up for 7 days and MIC was estimated in cases which were culture positive. Clinical and Laboratory Standard Institute's 2011 supplement on "Performance standards for antimicrobial susceptibility, report that an organism is considered to be sensitive, have intermediate sensitivity and resistant to ciprofloxacin if the MIC for ciprofloxacin is $<1,2$ and $>4$, respectively. This criteria for interpreting sensitivity to ciprofloxacin does not hold for gonococci. For babies with sterile blood culture, the above three MIC values were used to calculate Cmax/MIC.

\section{High Performance Liquid Chromatography (HPLC) Assay}

The samples were analyzed for ciprofloxacin concentration by high performance liquid chromatography, using Discovery ®HS C18 column $(25 \mathrm{~cm} \times 4.6 \mathrm{~mm}, 5 \mu \mathrm{m})$. The mobile phase was $14.5 \mathrm{mM}$ phosphate buffer with $\mathrm{pH} 3(75 \%)$ and methanol $(25 \%)$, at a flow rate of $1 \mathrm{ml} /$ minute and detected at $277 \mathrm{~nm}$. Samples were extracted by simple protein precipitation using zinc sulphate and methanol, with ornidazole as internal standard. Imprecision calculated as the interday coefficients for the quality control $(5 \mu \mathrm{g} / \mathrm{ml})$ was $4.2 \%$. There were no interferences from the medications commonly administered within this population.

\section{RESULTS}

A total of 95 neonates were recruited into the study from June 2010 to June 2011. Of which 30 babies were very preterm (28-31 wks), 35 moderately preterm (32$36 \mathrm{wks})$ and 30 term ( 37 weeks and above). The mean (SD) ciprofloxacin peak and trough concentrations are reported in table 1 .

As seen in table 2, there was poor correlation between both the age and birth weight with ciprofloxacin concentrations in all the three gestational age groups. One way Anova with bonferroni correction showed no significant difference in the trough $(\mathrm{p}$ value $=0.121$ ) or peak measurements ( $p$ value $=0.765$ ) between the groups.

Blood culture isolates were positive in 18 babies (19\%) and MIC was done for 14 blood culture isolates. The organisms isolated were B. Cepacia $(n=6)$, Klebsiella $(n=4)$, Staphylococcus Aureus $(n=2)$, Enterococcus $(n=1)$, E.coli $(n=1)$ and non fermenting gram negative bacilli $(n=1)$. Five of the strains were sensitive to ciprofloxacin (Staphylococcus Aureus, B. Cepacia, Klebsiella and GFNB), three (Enterococci, B.Cepacia) had intermediate sensitivity and 6 strains (Staphylococcus Aureus, B.Cepacia, Klebsiella.E.coli) were resistant to ciprofloxacin. 
Table 1: The mean (sd) ciprofloxacin levels and the co efficient of variation of the peak and trough values of the three gestational age groups.

\begin{tabular}{|c|c|c|c|}
\hline Parameters & $\begin{array}{c}\text { Very preterm } \\
(\mathbf{n}=\mathbf{3 0})\end{array}$ & $\begin{array}{c}\text { Moderately preterm } \\
(\mathbf{n}=\mathbf{3 0})\end{array}$ & $\begin{array}{c}\text { Term } \\
(\mathbf{n}=\mathbf{3 0})\end{array}$ \\
\hline Mean $(\mathrm{sd})$ Trough $(\mu \mathrm{g} / \mathrm{ml})$ & $\mathbf{4 . 0 1}( \pm \mathbf{1 . 8 0})$ & $\mathbf{2 . 5 4}( \pm \mathbf{1 . 2 6})$ & $\mathbf{3 . 2 1}( \pm \mathbf{1 . 9 9})$ \\
\hline Mean $(\mathrm{sd})$ Peak $(\mu \mathrm{g} / \mathrm{ml})$ & $\mathbf{1 2 . 0 7}( \pm \mathbf{3 . 6 3})$ & $\mathbf{8 . 6 8}( \pm \mathbf{3 . 6 1})$ & $\mathbf{1 2 . 5 5}( \pm \mathbf{4 . 9 4 5})$ \\
\hline $\begin{array}{c}\text { Co efficient of variation of trough } \\
\text { values }(\%)\end{array}$ & $\mathbf{4 8 . 8}$ & $\mathbf{4 9 . 2}$ & $\mathbf{7 0 . 3}$ \\
\hline $\begin{array}{c}\text { Co efficient of Variation of Peak } \\
\text { values }(\%)\end{array}$ & $\mathbf{3 6 . 4}$ & $\mathbf{4 1 . 8}$ & $\mathbf{4 4 . 6}$ \\
\hline
\end{tabular}

$\mathrm{n}$ - Number of subjects, sd- standard deviation, $\mu \mathrm{g} / \mathrm{ml}$ - microgram/millilitre

Table 2: Correlation between the age and ciprofloxacin levels and birth weight and ciprofloxacin levels in all the three gestational age groups

\begin{tabular}{|c|c|c|c|}
\hline Correlation & $\begin{array}{c}\text { Very preterm } \\
(\mathbf{n}=\mathbf{3 0})\end{array}$ & $\begin{array}{c}\text { Moderately preterm } \\
(\mathbf{n = 3 0})\end{array}$ & $\begin{array}{c}\text { Term } \\
(\mathbf{n}=\mathbf{3 0})\end{array}$ \\
\hline Age and trough & $\mathbf{- 0 . 3 6}$ & $\mathbf{0 . 2 3}$ & $\mathbf{- 0 . 0 1}$ \\
\hline Age and Peak & $\mathbf{0 . 3 9}$ & $\mathbf{- 0 . 2 2}$ & $\mathbf{- 0 . 1}$ \\
\hline Birth weight and trough & $\mathbf{- 0 . 0 4}$ & $\mathbf{0 . 2 2}$ & $\mathbf{- 0 . 1 8}$ \\
\hline Birth weight and peak & $\mathbf{- 0 . 1 3 6}$ & $\mathbf{0 . 2 2}$ & $\mathbf{- 0 . 0 5}$ \\
\hline
\end{tabular}

n- Number of subjects

The MIC of ciprofloxacin for sensitive strains, strains with intermediate sensitivity and resistant strains ranged from 0.023 to $0.75 \mu \mathrm{g} / \mathrm{mL}, 2 \mathrm{ug} / \mathrm{ml}$ and from 4 to 32 $\mu \mathrm{g} / \mathrm{mL}$ respectively.

The $\mathrm{C}_{\max } / \mathrm{MIC}$ for sensitive strains was above 10 . The $\mathrm{C}_{\max } / \mathrm{MIC}$ for strains of intermediate sensitivity to ciprofloxacin ranged from 4.09 to 9.62 . And that for resistant strains ranged from 0.31 to 3.47 .

Among the babies with sterile blood culture reports, $74.07 \%$ of them would have $\mathrm{C}_{\max } / \mathrm{MIC}>10$ if all grew organisms sensitive to ciprofloxacin. Only $7.41 \%$ would have $\mathrm{C}_{\max } / \mathrm{MIC}>10$ if they grew organisms with intermediate sensitivity and none would attain the required $\mathrm{C}_{\max } / \mathrm{MIC}$ if they grew resistant strains.

\section{DISCUSSION}

Ciprofloxacin serum concentration was not significantly different between babies in the three gestational age groups. The probable reason being that changes with respect to body water, liver and kidney maturation may not affect ciprofloxacin pharmacokinetics in neonates. A detailed pharmacokinetic study is required to explain this, which at the same time may be extremely difficult due to ethical considerations regarding number of blood samples in critically ill neonates.

The trough and peak concentrations (collected within 10 minutes of the end of infusion) of ciprofloxacin measured in term and preterm neonates in this study were higher compared to that in neonates from North India, in whom the mean trough and peak measurements (collected 15 minutes after the end of infusion) ranged from 0.7 to $1.0 \mu \mathrm{g} / \mathrm{ml}$ and from 2.3 to $3.0 \mu \mathrm{g} / \mathrm{ml}$ respectively. ${ }^{15}$ Van den Oever, H.L. et al and Bannon, M.J et al also reported ciprofloxacin trough and peak measurements, in the lower range. ${ }^{13,16}$ The increased concentration in peak and trough could be attributed to genetic variability contributing to difference in metabolism and clearance.

Blood culture growth was followed up till 7days, as most of the culture reports were positive by about 72 hours. ${ }^{17,}{ }^{18}$ B.Cepacia was the most common organism isolated but the MIC for each strain was different. Since the time point of the incidence of sepsis with this organism was different, the implication was that the source of infection was different.

In neonates with culture positive reports, the $\mathrm{C}_{\max } / \mathrm{MIC}$ was above 10 for sensitive strains but for strains of intermediate sensitivity or resistant to ciprofloxacin the target $\mathrm{C}_{\max } / \mathrm{MIC}$ was not reached. Surprisingly in babies with sterile culture reports, inspite of the higher concentration of ciprofloxacin in our population, $\mathrm{Cmax} / \mathrm{MIC}$ would be inadequate (ie <10) in more than $25 \%$ of patients, if infected with sensitive organisms. And if infected with organisms of intermediate sensitivity only $7.41 \%$ of babies would achieve adequate Cmax/MIC. If the organism showed resistance to ciprofloxacin, no baby would achieve an adequate Cmax/MIC. The wide inter-patient variability in trough and peak concentration of ciprofloxacin especially in term babies may be a reason for promoting emergence of resistance even if dosing was based on weight. This is supported by the lack of correlation between birth 
weight and serum ciprofloxacin concentration in neonates. Our neonates may need to be treated with a higher dose to improve Cmax/MIC and to check promotion of further resistance to ciprofloxacin. But to our knowledge more work needs to be done using higher doses and studying their side effects in neonates.

\section{CONCLUSION}

The current recommended dose of intravenous ciprofloxacin might be adequate for treating sepsis due to susceptible organisms, in the Indian neonate population. However higher dosing regimens may need to be adopted, after confirming its safety in neonates, when ciprofloxacin is used for organisms with intermediate susceptibility or with resistant organisms.

\section{CONFLICT OF INTEREST}

We like to declare that there is no conflict of interest in terms of personal or financial relationship with respect to of publication of this study.

\section{Acknowledgement}

We would like to sincerely thank the technicians from the Clinical Pharmacology Unit, Christian Medical College Hospital, Vellore for their help with of the concentration of serum ciprofloxacin. We would like to sincerely thank the technicians from Department of Microbiology, Christian Medical College Hospital, Vellore for their help with estimation of MIC.

\section{REFERENCES:}

1. MhairiG.Mac Donald MaDM, Mary.M.K.Sheshia. Avery's Neonatology.Pathophysiology and Management of the newborn. 6 th Edition. Philadelphia: Lippincott Williams and Wilkins; 2005.

2. National Neonatology Forum of India. National Neo-natalPerinatal Database, Report for the year 2000, New Delhi; Publ Noble Vision, p. 18-19.

3. World Health Statistics 2010

4. Ahmed ASMNU, Khan NZ, Saha SK, Chowdhury MAKA, Muslima H, Law P, et al. Ciprofloxacin treatment in preterm neonates in Bangladesh: lack of effects on growth and development. Pediatr. Infect. Dis. J. [Internet]. 2006 Dec [cited 2011 Oct 14];25(12):1137-41. Available from: http://www.ncbi.nlm.nih.gov/pubmed/17133159

5. Dutta S, Chowdhary G, Kumar P, Mukhopadhay K, Narang A. Ciprofloxacin administration to very low birth weight babies has no effect on linear growth in infancy. J. Trop. Pediatr. [Internet]. 2006 Apr [cited 2011 Oct 14];52(2):103-6. Available from: http://www.ncbi.nlm.nih.gov/pubmed/16115839

6. Lo W-T, Wang C-C, Lee C-M, Chu M-L. Successful treatment of multi-resistant Stenotrophomonas maltophilia meningitis with ciprofloxacin in a pre-term infant. European Journal of Pediatrics
[Internet]. 2002 Dec 1 [cited 2011 Oct 14];161:680-2. Available from: http://www.springerlink.com/content/vk5y29rrgetc9dwm/

7. Tanase-Derkaoui D, Le Huidoux P, Farnoux C, El-Moussawi F, Mariani-Kurkdjian P, Bingen E, et al. [Two cases of Pseudomonas aeruginosa neonatal meningitis treated by ciprofloxacine]. Arch Pediatr [Internet]. 2006 Oct [cited 2011 Oct 14];13 Suppl 1:S1721. Available from:

http://www.ncbi.nlm.nih.gov/pubmed/17370392

8. Belet N, Haciömeroğlu P, Küçüködük S. Ciprofloxacin treatment in newborns with multi-drug-resistant nosocomial Pseudomonas infections. Biol. Neonate [Internet]. 2004 [cited 2011 Oct 14];85(4):263-8. Available from: http://www.ncbi.nlm.nih.gov/pubmed/14739554

9. Zelenitsky SA, Harding GKM, Sun S, Ubhi K, Ariano RE. Treatment and outcome of Pseudomonas aeruginosa bacteraemia: an antibiotic pharmacodynamic analysis. J. Antimicrob. Chemother. [Internet]. 2003 Oct [cited 2011 Oct 14];52(4):66874. Available from: http://www.ncbi.nlm.nih.gov/pubmed/12951354

10. Kashuba AD M., Bertino JS, Nafziger AN. Dosing of Aminoglycosides To Rapidly Attain Pharmacodynamic Goals and Hasten Therapeutic Response by Using Individualized Pharmacokinetic Monitoring of Patients with Pneumonia Caused by Gram-Negative Organisms. Antimicrob. Agents Chemother. [Internet]. 1998 Jul 1 [cited 2011 Oct 14];42(7):1842-4. Available from: http://aac.asm.org/cgi/content/abstract/42/7/1842

11. Van Bambeke F, Michot J -M, Van Eldere J, Tulkens PM. Quinolones in 2005: an update. Clinical Microbiology and Infection [Internet]. 2005 Apr 1 [cited 2011 Oct 14]; 11(4):25680. Available from:

http://onlinelibrary.wiley.com/doi/10.1111/j.14690691.2005.01131.x/abstract

12. JL, AG, LM, ST, JS, HH, et al. Ciprofloxacin pharmacokinetic profiles in paediatric sepsis: how much ciprofloxacin is enough? Intensive Care Medicine [Internet]. 2002 Apr 1 [cited 2011 Oct 14]; 28:493-500. Available from: http://www.springerlink.com/content/v9ep5nfndp6knjvp/

13. Van den Oever HL, Versteegh FG, Thewessen EA, Van den Anker JN, Mouton JW, Neijens HJ. Ciprofloxacin in preterm neonates: case report and review of the literature. Eur. J. Pediatr. [Internet]. 1998 Oct [cited 2011 Oct 14];157(10):843-5. Available from: http://www.ncbi.nlm.nih.gov/pubmed/9809826

14. Nielsen EI, Sandström M, Honoré PH, Ewald U, Friberg LE. Developmental Pharmacokinetics of Gentamicin in Preterm and Term Neonates. Clinical Pharmacokinetics [Internet]. 2009 Jun [cited 2011 Oct 14];48:253-63. Available from: http://adisonline.com/pharmacokinetics/Abstract/2009/48040/Dev elopmental Pharmacokinetics of Gentamicin in.3.aspx

15. Aggarwal P, Dutta S, Garg S, Narang A. Multiple dose pharmacokinetics of ciprofloxacin in preterm babies. Indian Pediatr. 2004; 41:1001-7.

16. Bannon MJ, Stutchfield PR, Weindling AM, Damjanovic V. Ciprofloxacin in neonatal Enterobacter cloacae septicaemia. Arch Dis Child. 1989 Oct; 64(10 Spec No):1388-91.

17. Janjindamai W, Phetpisal S. Time to positivity of blood culture in newborn infants. 2006;

18. Kumar Y, Qunibi M, Neal T, Yoxall C. Time to positivity of neonatal blood cultures. Arch Dis Child Fetal Neonatal Ed. 2001 Nov; 85(3):F182-F186. 